In Memoriam

\title{
In Memoriam, Dr. Peter Fisher
}

Jennifer Jacobs ${ }^{1}$

${ }^{1}$ Department of Epidemiology, School of Public Health and Community Medicine, University of Washington, Seattle, Washington, United States

Homeopathy 2018;107:227.

Our community has suffered an irreplaceable loss-that of Dr. Peter Fisher, a shining beacon of light for homeopathy. Peter was, without a doubt, the most articulate, knowledgeable, and passionate proponent of homeopathy in the entire world. He was also kind, patient, and generous with his time, always willing to attend conferences, speak at government hearings, or co-author an article. He was the go-to person for anyone needing a calm, sensible voice to defend homeopathy against increasingly scurrilous claims.

I knew Peter for more than 30 years as a friend and colleague, and visited his home on several occasions.
I sometimes worried that he worked too hard, with all of his responsibilities at the Royal London Homeopathic Hospital, as editor of the journal Homeopathy, as a researcher, and as a clinician. But he did take time out to enjoy gardening, cooking, and vacationing with his family. It is hard to believe that he is gone, and that we will never again experience his brilliant mind or his droll, biting, wit. Although no-one can ever fill his shoes, we must all dedicate ourselves to moving homeopathy forward and keeping his legacy alive.
Address for correspondence Jennifer Jacobs, MD, MPH, School of Public Health and Community Medicine, University of Washington, Seattle, Washington, United States (e-mail: jjacobs@igc.org).
Copyright $(2018$ The Faculty of Homeopathy
DOI https://doi.org/

10.1055/s-0038-1675240. ISSN 1475-4916. 